\title{
Examination of clinical data and semen analysis results of patients undergoing orchiectomy for testicular tumor
}

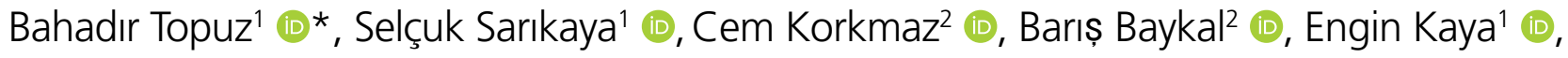

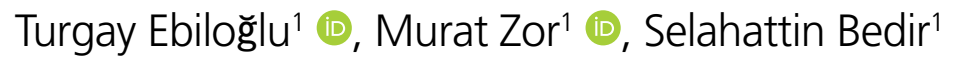

\begin{abstract}
SUMMARY
OBJECTIVE: Testicular tumor constitutes $1 \%$ of male neoplasms. Infertility can be determined in patients with testicular tumors before orchiectomy due to the deterioration of spermatogenesis. The aim of this study was to show the clinical, radiological, and pathological characteristics and spermiogram results of patients with testicular tumor and their relationship with each other.

METHODS: The data of patients who underwent orchiectomy due to testicular tumor between 2016 and 2019 were reviewed retrospectively. These data included sociodemographic data of the patients, pretreatment spermiogram characteristics, level of serum tumor markers, characteristics of the ultrasonography, type of orchiectomy, and histopathological examination.

RESULTS: This study included 53 male patients, with a mean age of $33.51 \pm 12.86$ years. The mean levels of all tumor markers were above the reference levels. The mean tumor size was $34.68 \pm 23.32 \mathrm{~mm}$. Multiple localizations and microlithiasis were detected in 11.3 and $13.2 \%$ of the tumors, respectively. The most common masses were hypoechoic $(n=37 ; 69.8 \%)$ and hypervascular $(n=47 ; 81 \%)$. Spermiogram and cryopreservation were performed in 29 (54.7\%) of 53 patients preoperatively. The mean sperm concentration before orchiectomy was $24.21 \times 10 \% \mathrm{~mL}$ and group A sperm motility $0.79 \%$, group B sperm motility $39.10 \%$, group C sperm motility $9.83 \%$, and group D sperm motility $22.69 \%$ in testicular tumors.

CONCLUSION: Spermatogenesis adversely affected before the treatment due to local and systemic effects of testicular cancer. Fertility expectations can be increased in the subsequent years by semen analysis and referral to cryopreservation.

KEYWORDS: Cryopreservation. Infertility. Orchiectomy. Semen analysis. Testicular neoplasms.
\end{abstract}

\section{INTRODUCTION}

Testicular tumor constitutes $1 \%$ of male neoplasms and $5 \%$ of all urologic tumors ${ }^{1}$. In developed countries, the most common type of cancer in men aged 15-44 years is testicular tumor ${ }^{2,3}$. Alpha-fetoprotein (AFP), $\beta$-human chorionic gonadotropin $(\beta-h C G)$, and lactate dehydrogenase (LDH) are used as serum tumor markers in testicular tumors and also contribute to diagnosis and staging ${ }^{4}$. The color Doppler ultrasonography is the main imaging method used to investigate the presence of a mass in the testis 5

There is a $30 \%$ reduction in fertilization in patients with testicular cancer due to subsequent or spontaneous treatments ${ }^{6}$. Natural paternity rate for these patients is about $50 \%$ due to treatments such as orchiectomy, retroperitoneal lymph node dissection, radiotherapy, or chemotherapy continuously for 10 years ${ }^{6,7}$. Therefore, it is recommended that patients undergo

\footnotetext{
'Gulhane Training and Research Hospital, Department of Urology - Ankara, Turkey.

${ }^{2}$ Gulhane Training and Research Hospital, In Vitro Fertilization Center - Ankara, Turkey.

*Corresponding author: drbtopuz@gmail.com

Conflicts of interest: the authors declare there are no conflicts of interest. Funding: none.

Received on January 14, 2021. Accepted on January 15, 2021.
} 
semen analysis and cryopreservation before orchiectomy, radiotherapy, or gonadotoxic chemotherapy ${ }^{4,6,8}$.

Decreased sperm parameters may be detected before orchiectomy due to the deterioration of spermatogenesis. The causes of this condition may include systemic effects, hormonal changes, autoimmune effects, changes in local blood flow, and increased intrascrotal temperature ${ }^{8-10}$. In our clinic, patients with testicular cancer are offered pretreatment semen analysis and cryopreservation to increase fertility expectancy parallel to the improvements in assisted reproductive technology ${ }^{11,12}$.

We suppose that semen analysis of patients with testicular cancer should be evaluated preoperatively because of their predisposition to infertility. The rationale of this study was to investigate the factors that may cause the decreased infertility by using pretreatment clinical semen parameters and to examine the radiological, biochemical, and pathological data.

\section{METHODS}

\section{Patients}

This is a retrospective study. The data of patients who underwent partial or radical orchiectomy due to testicular tumor between 2016 and 2019 were reviewed. Sixty-five patients underwent orchiectomy in our clinic. Twelve patients who undergone orchiectomy except testicular tumor, such as torsion, atrophic testis, testicular abscess, and undescended testis, were excluded from the study. The data of 53 patients who underwent partial or radical orchiectomy due to testicular tumor were included in this study. All of these patients were 16 years or older.

\section{Data collection}

Serum AFP, $\beta$-hCG, and LDH levels were determined before orchiectomy. The Doppler ultrasonography data were used to determine the side, location, number, size, echogenicity, blood supply of the testicular mass, and testicular microlithiasis. The magnetic resonance imaging was performed in addition to ultrasonography for differential diagnosis of some masses. In some testicular masses, the intraoperative frozen examination was used. According to the results of the frozen examination, partial or radical orchiectomy was performed on the testicular mass. The histopathological results of the testicular mass were examined. Patients were offered to give spermiogram and to have cryopreservation by masturbation before orchiectomy. Both spermiogram and cryopreservation were evaluated by an experienced technician at the Assisted Reproductive Techniques Center in our hospital. In the spermiogram analysis, motility (i.e., total, progressive, and nonprogressive) and concentration were evaluated according to the World Health Organization (WHO) 2010 guidelines $^{13}$.
Sperm samples were obtained after 2-3 days of sexual abstinence. The semen was stored in the hospital in a sterile container and delivered to the laboratory within $1 \mathrm{~h}$. The volume of seminal fluid was measured using a graded tube. The concentration was measured in an improved Neubauer chamber, with a magnification of 200x. A minimum of five power fields were examined, and for each field at least 200 spermatozoa were analyzed ${ }^{14}$. According to the WHO 2010 criteria and some studies, the minimum percentage of group A (rapidly progressive) + B (slowly progressive) (i.e., $A+B=$ progressive motility) sperm motility should be $32 \%$, and minimum percentage of group $\mathrm{A}$ (rapidly progressive) $+\mathrm{B}$ (slowly progressive) $+\mathrm{C}$ (non-progressive) (i.e., $\mathrm{A}+\mathrm{B}+\mathrm{C}=$ total motility) sperm motility should be $40 \%$ for the fertilization ${ }^{13,15}$. To better understand the results of semen analysis by urologists and patients, the sperm motility was expressed in both forms, i.e., $A, B, C, D$, and $A+B$ and $A+B+C$. Semen samples were frozen in TEST-egg yolk buffer (TYB; Irvine Scientific, Santa Ana, CA, USA) in a $1: 1$ ratio and stored in liquid nitrogen at $-196^{\circ} \mathrm{C}$.

\section{Statistical analysis}

The sample size was calculated with the help of sample size calculator at www.calculator.net. Examining $>51$ patients was found to be sufficient for this study with $95 \%$ confidence level, 5\% standard deviation expectancy, and estimated 110 general population size. The statistical analysis was performed using the SPSS version 22.0 software (IBM Corp., Armonk, NY, USA). The descriptive data were expressed in mean and standard deviation (SD), median (min-max), number, and frequency. The Kolmogorov-Smirnov test was used to check the normality of data for quantitative variables. The one-way ANOVA test was used to compare variables, and for all the statistical analyses the two-sided $\mathrm{p}<0.05$ was considered as statistically significant.

\section{RESULTS}

This study included 53 male patients, with a mean age of $33.51 \pm 12.86$ years. All patients were evaluated with tumor markers preoperatively. Sociodemographic data, levels of serum tumor marker, color Doppler ultrasonography data, and histopathological diagnosis of the patients are shown in Table 1 . Preoperative magnetic resonance imaging was performed in $3(5.7 \%)$ patients to support the diagnosis of testicular mass.

In 12 of 53 patients (22.6\%), the intraoperative frozen examination was used. As a result, 4 (7.5\%) of these patients underwent partial orchiectomy and 49 (92.5\%) underwent radical orchiectomy. In the final histopathological examination, 1 (1.9\%) patient had burned-out tumor, 7 (13.2\%) patients had benign tumors, and 45 (84.9\%) patients had malignant tumors. 
Spermiogram and cryopreservation were performed in 29 $(54.7 \%)$ of 53 patients preoperatively. The spermiogram results of the patients are shown in Table 2 . There was no statistically significant difference than the normal criteria. In 29 patients who underwent spermiogram prior to orchiectomy, the percentage of group A motility was found to be $0 \%$ in $27,6 \%$ in 1 , and $17 \%$ in 1. According to the spermiogram results, 6 (20.6\%) of 29 patients had sperm concentration $<1 \times 10^{6} / \mathrm{mL}$ with a few motile sperm, and $1(3.44 \%)$ patient had azoospermia.
We aimed to investigate whether patient age and pathological subtype have an effect on other data. Therefore, the patients were divided into three groups according to age: Group 1 (10-30 years), Group 2 (31-50 years), and Group 3 (51-90 years). There was no statistically significant difference between age groups in terms of tumor markers, spermiogram results, tumor location, and tumor size parameters (Table 3). No statistically significant difference was found in terms of spermiogram results and tumor location parameters according to pathological diagnoses (Table 3).

Table 1. Sociodemographic, biochemical, ultrasound, and histopathological characteristics of patients.

\begin{tabular}{|c|c|c|}
\hline \multicolumn{3}{|c|}{ Sociodemographic characteristics } \\
\hline \multirow{3}{*}{$\mathrm{BMI}\left(\mathrm{kg} / \mathrm{m}^{2}\right)$} & Mean \pm SD & Min-Max \\
\hline & $24.73 \pm 4.22$ & $18.44-34.28$ \\
\hline & $\mathrm{n}$ & $\%$ \\
\hline \multicolumn{3}{|l|}{ Comorbidity } \\
\hline Diabetes mellitus & 2 & 3.78 \\
\hline Arterial hypertension & 1 & 1.89 \\
\hline Respiratory diseases & 2 & 3.78 \\
\hline Hyperlipidemia & 3 & 5.66 \\
\hline Arthritis & 1 & 1.89 \\
\hline None & 44 & 83 \\
\hline \multicolumn{3}{|l|}{ Cigarette smoking } \\
\hline Yes & 18 & 33.9 \\
\hline No & 37 & 66.1 \\
\hline \multicolumn{3}{|l|}{ Education degree } \\
\hline Elementary and secondary school & 11 & 20.7 \\
\hline High school & 24 & 45.2 \\
\hline University & 18 & 34.1 \\
\hline \multicolumn{3}{|l|}{ Marital status } \\
\hline Single & 34 & 64.1 \\
\hline Married & 19 & 35.9 \\
\hline \multicolumn{3}{|l|}{ Serum tumor markers } \\
\hline & Mean \pm SD & Min-Max \\
\hline AFP (normal range: 0-9 ng/mL) & $351.47 \pm 2069.76$ & $0.605-15002$ \\
\hline$\beta$-hCG (normal range: $0.5-2.67 \mathrm{mlU} / \mathrm{mL}$ ) & $1086.27 \pm 6441.63$ & $0.10-45945$ \\
\hline LDH (normal range: 0-248 U/L) & $258.75 \pm 244.31$ & $115-1872$ \\
\hline \multicolumn{3}{|l|}{ Color Doppler ultrasound } \\
\hline \multirow{3}{*}{ Size $(\mathrm{mm})$} & Mean \pm SD & Min-Max \\
\hline & $34.68 \pm 23.32$ & $5-120$ \\
\hline & $\mathrm{n}$ & $\%$ \\
\hline \multicolumn{3}{|l|}{ Location } \\
\hline Scrotal & 52 & 98.1 \\
\hline Inguinal & 1 & 1.9 \\
\hline
\end{tabular}


Table 1. Continuation.

\begin{tabular}{|c|c|c|}
\hline \multicolumn{3}{|c|}{ Sociodemographic characteristics } \\
\hline \multirow{3}{*}{$\mathrm{BMI}\left(\mathrm{kg} / \mathrm{m}^{2}\right)$} & Mean $\pm S D$ & Min-Max \\
\hline & $24.73 \pm 4.22$ & $18.44-34.28$ \\
\hline & $n$ & $\%$ \\
\hline \multicolumn{3}{|l|}{ Laterality } \\
\hline Right & 28 & 52.8 \\
\hline Left & 25 & 42.2 \\
\hline \multicolumn{3}{|l|}{ Microlithiasis } \\
\hline Yes & 7 & 13.2 \\
\hline No & 46 & 86.8 \\
\hline \multicolumn{3}{|l|}{ Multifocality } \\
\hline Single & 47 & 88.7 \\
\hline Multiple & 6 & 11.3 \\
\hline \multicolumn{3}{|l|}{ Localization } \\
\hline Upper pole & 13 & 24.5 \\
\hline Middle pole & 12 & 22.6 \\
\hline Lower pole & 10 & 18.9 \\
\hline Upper + Middle pole & 2 & 3.8 \\
\hline Middle + Lower pole & 4 & 7.5 \\
\hline Complete & 12 & 22.6 \\
\hline \multicolumn{3}{|l|}{ Echogenicity } \\
\hline Hyperechoic & 1 & 1.9 \\
\hline Hypoechoic & 37 & 69.8 \\
\hline Heterogeneous echo & 10 & 18.9 \\
\hline Isoechoic & 3 & 5.7 \\
\hline Missing & 2 & 3.8 \\
\hline \multicolumn{3}{|l|}{ Blood flow } \\
\hline None & 3 & 5.7 \\
\hline Low & 2 & 3.8 \\
\hline Mild & 5 & 9.4 \\
\hline High & 43 & 81.1 \\
\hline \multicolumn{3}{|c|}{ Histopathological evaluation } \\
\hline & $\mathrm{n}$ & $\%$ \\
\hline Seminoma (classic) & 22 & 41.5 \\
\hline Mixt germ cell tumor & 16 & 30.2 \\
\hline Embryonal carcinoma & 2 & 3.8 \\
\hline Adenomatoid tumor & 2 & 3.8 \\
\hline Teratocarcinoma & 1 & 1.9 \\
\hline Lymphoma & 1 & 1.9 \\
\hline Seminoma (spermatocytic) & 1 & 1.9 \\
\hline Teratoma (postpubertal) & 1 & 1.9 \\
\hline Retroperitoneal germ cell tumor & 1 & 1.9 \\
\hline Leydig cell tumor & 1 & 1.9 \\
\hline
\end{tabular}


Table 1. Continuation.

\begin{tabular}{|c|c|c|}
\hline \multicolumn{3}{|c|}{ Sociodemographic characteristics } \\
\hline \multirow{3}{*}{ BMI $\left(\mathrm{kg} / \mathrm{m}^{2}\right)$} & Mean $\pm S D$ & Min-Max \\
\hline & $24.73 \pm 4.22$ & $18.44-34.28$ \\
\hline & $n$ & $\%$ \\
\hline Lipoma & 1 & 1.9 \\
\hline Testicular fibroma & 1 & 1.9 \\
\hline Leydig cell proliferation & 1 & 1.9 \\
\hline Epidermoid cyst & 1 & 1.9 \\
\hline Leiomyoma & 1 & 1.9 \\
\hline
\end{tabular}

BMI: body mass index; AFP, alpha-fetoprotein; $\beta$-hCG, $\beta$-human chorionic gonadotropin; LDH, lactate dehydrogenase.

Table 2. Summary of spermiogram results.

\begin{tabular}{l|c|c} 
& Spermiogram results \\
\hline Concentration $(10 \% \mathrm{~mL})$ & Mean \pm SD & Min-Max \\
\hline Group A motility (\%) & $24.21 \pm 26.81$ & $0-115$ \\
\hline Group B motility (\%) & $0.79 \pm 3.31$ & $0-17$ \\
\hline Group C motility (\%) & $39.10 \pm 29.84$ & $0-81$ \\
\hline Group D motility (\%) & $9.83 \pm 12.20$ & $0-50$ \\
\hline
\end{tabular}

\section{DISCUSSION}

The aim of this study was to investigate the factors that may cause the decreased infertility by using pretreatment clinical semen parameters and to examine the radiological, biochemical, and pathological data.

In testicular cancer, the levels of serum tumor markers should be checked following history and physical examination in patients with suspected testicular cancer ${ }^{16,17}$. In our series, the mean levels of all tumor markers were above the reference levels, with AFP: $351.47 \pm 2069.76 \mathrm{ng} / \mathrm{mL}, \beta$-hCG: 1086.27 $\pm 6441.63 \mathrm{mIU} / \mathrm{mL}$, and LDH: $258.75 \pm 244.31 \mathrm{U} / \mathrm{L}$.

The present guidelines recommend Doppler ultrasonography to investigate all men with testicular mass before orchiectomy ${ }^{18,19}$. According to one of the earlier studies, among the total of 107 patients, 50 had right testicular mass, 56 had left testicular mass, and 1 had bilateral testicular mass ${ }^{20}$. It was stated that the mean patient age was 29 years, and the tumor size was $34.8 \mathrm{~mm}$. The ultrasonographic evaluation of the masses revealed 18 (16.9\%) multiple tumors, 32 (29.5\%) microlithiasis, and 70 (63.8\%) hypoechoic masses. In our study, testicular mass was detected more frequently on the right side $(52.8 \%)$. The mean tumor size was similar to the earlier study. Unlike the earlier study, multiple localization and microlithiasis were detected in 11.3 and $13.2 \%$ of the tumors, respectively. Although the incidence of microlithiasis in testicular tumors reaches up to $48 \%$ in some studies, it is generally detected at a rate of $15-20 \%{ }^{21}$. We detected the testicular microlithiasis at a rate similar to that in the literature (13.2\%). The most common masses were hypoechoic $(\mathrm{n}=37 ; 69.8 \%)$ and heterogeneous echo $(\mathrm{n}=10 ; 18.9 \%)$. In a study evaluating the relationship between the histological subtype and sonographic images of the masses, the information of a total of 58 patients was reported ${ }^{22}$. In the Doppler examination of the masses, $81 \%(\mathrm{n}=47)$ were reported as hypervascular, $14 \%(\mathrm{n}=8)$ as hypovascular, and $5 \%(\mathrm{n}=3)$ as avascular. Similarly, we found that the rate of hypervascular masses was approximately $81 \%$ $(\mathrm{n}=43)$. In fact, testicular masses usually show hypervascularity. The pathology of $3(5.7 \%)$ patients with avascular mass diagnosed by using Doppler was reported as testicular lipoma, epidermoid cyst, and interestingly, a classical seminoma. In a study examining a rather large series of patients, the characteristics of a total of 325 testicular tumors were shared ${ }^{23}$. A total of $79.8 \%(\mathrm{n}=197)$ hypoechogenic and $73.3 \%(\mathrm{n}=181)$ hypervascular masses were detected. In this study, the rates of these two sonographic data were $69.8 \%$ and $81.1 \%$, respectively, and they were quite high. Also in this study, the proportions of the 
Table 3. Evaluation variables according to age groups and pathological types.

\begin{tabular}{|c|c|}
\hline \multicolumn{2}{|c|}{ According to the age groups } \\
\hline & $p$ \\
\hline AFP & 0.655 \\
\hline B-hCG & 0.530 \\
\hline LDH & 0.784 \\
\hline A sperm motility (\%) & 0.472 \\
\hline B sperm motility (\%) & 0.563 \\
\hline C sperm motility (\%) & 0.896 \\
\hline D sperm motility (\%) & 0.387 \\
\hline Concentration & 0.489 \\
\hline Location & 0.649 \\
\hline Size & 0.206 \\
\hline \multicolumn{2}{|l|}{ Pathology types } \\
\hline Age group 1 vs. 2 & $>0.05$ \\
\hline Age group 2 vs. 3 & $<0.01$ \\
\hline Age group 1 vs. 3 & $<0.01$ \\
\hline \multicolumn{2}{|c|}{ According to the pathology types } \\
\hline & $p$ \\
\hline A sperm motility (\%) & 0.908 \\
\hline B sperm motility (\%) & 0.149 \\
\hline C sperm motility (\%) & 0.379 \\
\hline D sperm motility (\%) & 0.321 \\
\hline Motility & 0.885 \\
\hline Concentration & 0.099 \\
\hline Location & 1 \\
\hline
\end{tabular}

AFP, alpha-fetoprotein; $\beta$-hCG, $\beta$-human chorionic gonadotropin; LDH, lactate dehydrogenase.

masses covering the upper pole, middle pole, and the entire testis were found to be similar (24.5, 22.6, and $22.6 \%$, respectively). The magnetic resonance imaging was used to support differential diagnosis in 3 (5.7\%) patients after the sonographic evaluation.

The most common pathological subtype was seminoma $(\mathrm{n}=23 ; 43.4 \%)$, as in other studies. Spermatocytic seminoma was detected in a 71-year-old patient. Twelve patients among 53 $(22.6 \%)$ were evaluated intraoperatively by the frozen examination. The final pathology of the testicular masses using the frozen examination was reported as 4 benign and 8 malignant. The final pathology of $7(13.2 \%)$ testicular masses was reported as benign. When the benign masses were examined retrospectively, frozen examination was performed in 4 of them, and partial orchiectomy was performed according to the results obtained from the frozen examination. The subgroup distribution of these benign masses was as follows: lipoma $(n=1)$, epidermoid cyst $(n=1)$, and adenomatoid tumor $(n=2)$. According to the recent studies, partial orchiectomy with frozen examination and testis-sparing surgery is suggested for the small, non-palpable, incidentally detected testicular masses with no elevated tumor markers ${ }^{24,25}$. Our pathological results appear similar to those in the literature. In this study, it was determined that the spermiogram results did not differ according to histopathological diagnoses.

Spermatogenesis may be impaired in testicular tumors due to the destruction of the surrounding tissue, local secretion of $\beta$-hCG and some paracrine factors, increased intrascrotal temperature, autoimmune effects, and changes in local blood flow. Even in unilateral testicular cancer, spermatogenesis may be adversely affected in the contralateral testis. This situation reveals the tendency of the patients to infertility from the beginning. Negative changes in sexual life may occur in men with testicular cancer due to reduced sexual pleasure and desire. Testicular cancer can cause worse sperm density and motility, especially when compared with other cancers. In a study evaluating Danish males, those evaluated for infertility were 1.6 times more likely to develop testicular germ cell tumors following the infertility evaluations ${ }^{26}$. In another large-based study conducted in the United States, semen analysis showed that 24\% of men had infertility and that these men were 3 times more likely to be diagnosed with testicular cancer than the general population ${ }^{27}$. All these studies show the relationship between testicular cancer and low semen quality. In a recent study, semen parameters between seminoma type testicular cancer and control group were compared according to WHO 2010 criteria $^{9,13}$. A decrease in sperm motility $(\mathrm{p}=0.019)$, sperm concentration $(\mathrm{p}=0.003)$, total sperm count $(\mathrm{p}=0.001)$, and total motile sperm count $(\mathrm{p}=0.001)$ were found in the seminoma group. The mean sperm concentration was $46.72 \times 10^{6} / \mathrm{mL}$ in the tumor group. However, there was no information about the percentage of sperm in group A, B, C, and D motility. In our study, spermiogram and cryopreservation were performed before orchiectomy in more than half $(\mathrm{n}=29 ; 54.7 \%)$ of 53 patients treated for testicular mass. The reason why this procedure is not performed in the remaining patients is that some patients do not want to give semen and others are operated at night in emergency. It is remarkable that the percentage of group A motility $(0.79 \%)$ was found to be quite low. However, the group $A+B$ sperm motility ratio is above the reference value (32\%) with $39.89 \%$. In 29 patients who underwent spermiogram prior to orchiectomy, the percentage of group A motility was found to be $0 \%$ in $27,6 \%$ in 1 , and $17 \%$ in 1 . Low percentage of forward motile sperm indicates a higher risk of infertility before orchiectomy. Even in the pretreatment period, approximately 
$50 \%$ oligozoospermia and $24 \%$ azoospermia may occur in testicular cancer $^{28}$. According to our spermiogram results, 6 (20.6\%) of 29 patients had sperm concentration $<1 \times 10^{6} / \mathrm{mL}$ with a few motile sperm, and 1 patient (3.44\%) had azoospermia. We found that the number of patients with oligozoospermia was slightly lower than those in the earlier study $(n=12$; $41.3 \%)$. The average sperm concentration of patients with oligozoospermia was $5.25 \times 10^{6} / \mathrm{mL}$. In light of the data, it is noted that patients have a risk of infertility in the pre-orchiectomy period. It is certain that this risk will increase even more when chemotherapy or radiotherapy is added to the treatment after orchiectomy.

Although we provided important information about these patients, our study had some limitations. First, our patient population was not large. Second, we could not have spermiogram and cryopreservation in all patients before orchiectomy. Third, while examining the spermiograms of the patients, we could not evaluate them in terms of sperm morphology. Despite these limitations, it was important to show that patients may experience infertility risk, especially in the preoperative period.

\section{CONCLUSION}

Testicular cancer is more common in young men, and reproductive functions may be adversely affected in these patients. Currently, semen analysis and cryopreservation are recommended in patients with testicular cancer in the pretreatment period. Doctors who treat testicular cancer should be aware of fertility problems that may arise in patients in the future.

\section{ACKNOWLEDGMENTS}

The present study protocol was reviewed and approved by the Institutional Review Board of Gülhane Training and Research Hospital, Ankara, Turkey (2019/16 - 19/374).

\section{AUTHORS' CONTRIBUTIONS}

BT: Supervision, Writing - Original Draft. SS: Supervision, Writing-Original Draft. CK: Investigation. BB: Investigation. EK: Data Curation, Formal Analysis. TE: Data Curation, Formal Analysis. MZ: Data Curation. SB: Data Curation.

\section{REFERENCES}

1. La Vecchia C, Bosetti C, Lucchini F, Bertuccio P, Negri E, Boyle P, et al. Cancer mortality in Europe, 2000-2004, and an overview of trends since 1975. Ann Oncol. 2010;21(6):1323-60. https:// doi.org/10.1093/annonc/mdp530

2. Uçar MA, Arikan F, Coșkun HȘ, Kondak Y, Tatlı AM, Göksu SS. Fertility in testicular cancer patients: a single-centre study in Turkey. Int J Clin Oncol. 2020;25(3):495-500. https://doi. org/10.1007/s10147-019-01534-7

3. Trabert B, Chen J, Devesa SS, Bray F, McGlynn KA. International patterns and trends in testicular cancer incidence, overall and by histologic subtype, 1973-2007. Andrology. 2015;3(1):4-12. https://doi.org/10.1111/andr.293

4. Gilligan TD, Seidenfeld J, Basch EM, Einhorn LH, Fancher $\mathrm{T}$, Smith DC, et al. American Society of Clinical Oncology Clinical Practice Guideline on uses of serum tumor markers in adult males with germ cell tumors. J Clin Oncol. 2010;28(20):3388-404. https://doi.org/10.1200/ JCO.2009.26.4481

5. Shaw J. Diagnosis and treatment of testicular cancer. Am Fam Physician. 2008;77(4):469-74. PMID: 18326165

6. Moody JA, Ahmed K, Horsfield C, Pedersen MRV, Yap T, Shabbir M. Fertility preservation in testicular cancer predictors of spermatogenesis. BJU Int. 2018;122(2):23642. https://doi.org/10.1111/bju.14214

7. Matos E, Skrbinc B, Zakotnik B. Fertility in patients treated for testicular cancer. J Cancer Surviv. 2010;4(3):274-8. https://doi.org/10.1007/s11764-010-0135-9

8. Ostrowski KA, Walsh TJ. Infertility with testicular cancer. Urol Clin North Am. 2015;42(3):409-20. https://doi. org/10.1016/j.ucl.2015.05.003
9. Dias TR, Agarwal A, Pushparaj PN, Ahmad G, Sharma R. Reduced semen quality in patients with testicular cancer seminoma is associated with alterations in the expression of sperm proteins. Asian J Androl. 2020;22(1):88-93. https:// doi.org/10.4103/aja.aja_17_19

10. Vakalopoulos I, Dimou P, Anagnostou I, Zeginiadou T. Impact of cancer and cancer treatment on male fertility. Hormones (Athens). 2015;14(4):579-89. https://doi.org/10.14310/ horm.2002.1620

11. De Martin H, Cocuzza MS, Tiseo BC, Wood GJA, Miranda EP, Monteleone PAA, et al. Positive rheotaxis extended drop: a one-step procedure to select and recover sperm with mature chromatin for intracytoplasmic sperm injection. J Assist Reprod Genet. 2017;34(12):1699-1708. https://doi.org/10.1007/ s10815-017-1024-1

12. Franchim CS, Soares-Junior JM, Serafini PC, Monteleone PAA, Coccuzza MS, Zanardo EA, et al. Efficacy of MLPA for detection of Y-chromosome microdeletions in infertile Brazilian patients. J Assist Reprod Genet. 2020;37(5):1251-9. https:// doi.org/10.1007/s10815-020-01777-8

13. World Health Organization. WHO laboratory manual for the examination and processing of human semen. 5 th ed. Geneva: World Health Organization; 2010.

14. Hamilton JA, Cissen M, Brandes M, Smeenk JM, de Bruin JP, Kremer JA, et al. Total motile sperm count: a better indicator for the severity of male factor infertility than the WHO sperm classification system. Hum Reprod. 2015;30(5):1110-21. https://doi.org/10.1093/humrep/dev058

15. Zhang $M H$, Zhang $A D$, Shi ZD, Wang LG, Qiu Y. Changes in levels of seminal nitric oxide synthase, macrophage migration 
inhibitory factor, sperm dna integrity and caspase-3 in fertile men after scrotal heat stress. PLoS One. 2015;10(10):e0141320. https://doi.org/10.1371/journal.pone.0141320

16. Sineath RC, Mehta A. Preservation of fertility in testis cancer management. Urol Clin North Am. 2019;46(3):341-51. https:// doi.org/10.1016/j.ucl.2019.04.010

17. Murray MJ, Huddart RA, Coleman N. The present and future of serum diagnostic tests for testicular germ cell tumours. Nat Rev Urol. 2016;13(12):715-25. https://doi.org/10.1038/ nrurol.2016.170

18. Beyer J, Albers P, Altena R, Aparicio J, Bokemeyer C, Busch J, et al. Maintaining success, reducing treatment burden, focusing on survivorship: highlights from the third European consensus conference on diagnosis and treatment of germ-cell cancer. Ann Oncol. 2013;24(4):878-88. https://doi.org/10.1093/annond/mds579

19. Honecker F, Aparicio J, Berney D, Beyer J, Bokemeyer C, Cathomas R, et al. ESMO Consensus Conference on testicular germ cell cancer: diagnosis, treatment and follow-up. Ann Oncol. 2018;29(8):1658-86. https://doi.org/10.1093/annonc/ mdy217

20. McDonald MW, Reed AB, Tran PT, Evans LA. Testicular tumor ultrasound characteristics and association with histopathology. Urol Int. 2012;89(2):196-202. https://doi. org/10.1159/000338771

21. Leblanc L, Lagrange $F$, Lecoanet $P$, Marçon $B$, Eschwege $P$, Hubert J. Testicular microlithiasis and testicular tumor: a review of the literature. Basic Clin Androl. 2018;28:8. https://doi. org/10.1186/s12610-018-0073-3

22. Kawamoto A, Hatano T, Saito K, Inoue R, Nagao T, Sanada $\mathrm{S}$. Sonographic classification of testicular tumors by tissue harmonic imaging: experience of 58 cases. Med Ultrason (2001). 2018;45(1):103-11. https://doi.org/10.1007/s10396017-0783-8

23. Song $G$, Xiong GY, Fan $Y$, Huang $C$, Kang YM, Ji GJ, et al. The role of tumor size, ultrasonographic findings, and serum tumor markers in predicting the likelihood of malignant testicular histology. Asian J Androl. 2019;21(2):196-200. https://doi. org/10.4103/aja.aja_119_18

24. Paffenholz P, Held L, Loosen SH, Pfister D, Heidenreich A. Testis Sparing Surgery for Benign Testicular Masses: Diagnostics and Therapeutic Approaches. J Urol. 2018;200(2):353-60. https:// doi.org/10.1016/j.juro.2018.03.007

25. Borghesi M, Brunocilla E, Schiavina R, Gentile G, Dababneh $H$, Della Mora $L$, et al. Role of testis sparing surgery in the conservative management of small testicular masses: oncological and functional perspectives. Actas Urol Esp. 2015;39(1):57-62. https://doi.org/10.1016/j. acuro.2014.02.020

26. Jacobsen R, Bostofte E, Engholm G, Hansen J, Olsen $\mathrm{JH}$, Skakkebaek NE, et al. Risk of testicular cancer in men with abnormal semen characteristics: cohort study. BMJ. 2000;321(7264):789-92. https://doi.org/10.1136/ bmj.321.7264.789

27. Walsh TJ, Croughan MS, Schembri M, Chan JM, Turek PJ. Increased risk of testicular germ cell cancer among infertile men. Arch Intern Med. 2009;169(4):351-6. https://doi. org/10.1001/archinternmed.2008.562

28. Howell SJ, Shalet SM. Effect of cancer therapy on pituitarytesticular axis. Int J Androl. 2002;25(5):269-76. https:// doi.org/10.1046/j.1365-2605.2002.00365.x 